\title{
CHARACTERISTICS OF THE REMOTE SENSING DATA USED IN THE PROPOSED UNFCCC REDD+ FOREST REFERENCE EMISSION LEVELS (FRELS)
}

\author{
B. A. Johnson ${ }^{\text {a, }}$, H. Scheyvens ${ }^{\text {a }}$, H. Samejima ${ }^{\text {a }}$, M. Onoda ${ }^{\text {a,b }}$ \\ ${ }^{a}$ Institute for Global Environmental Strategies, 2108-11 Kamiyamaguchi, Hayama, Kanagawa, 240-0115, Japan - (johnson, \\ scheyvens, samejima)@iges.or.jp \\ b Japan Aerospace Exploration Agency, Ochanomizu Sola City, 4-6 Kanda Surugadai, \\ Chiyoda-ku, Tokyo, 101-8008, Japan - onoda.masami@jaxa.jp
}

Commission VIII, WG VIII/7

KEY WORDS: Earth observation, climate change, land-use change, REDD+, forest carbon inventory, national forest monitoring system, deforestation, forest degradation

\begin{abstract}
:
Developing countries must submit forest reference emission levels (FRELs) to the UNFCCC to receive incentives for REDD+ activities (e.g. reducing emissions from deforestation/forest degradation, sustainable management of forests, forest carbon stock conservation/enhancement). These FRELs are generated based on historical $\mathrm{CO}_{2}$ emissions in the land use, land use change, and forestry sector, and are derived using remote sensing (RS) data and in-situ forest carbon measurements. Since the quality of the historical emissions estimates is affected by the quality and quantity of the RS data used, in this study we calculated five metrics (i-v below) to assess the quality and quantity of the data that has been used thus far. Countries could focus on improving on one or more of these metrics for the submission of future FRELs. Some of our main findings were: (i) the median percentage of each country mapped was $100 \%$, (ii) the median historical timeframe for which RS data was used was 11.5 years, (iii) the median interval of forest map updates was 4.5 years, (iv) the median spatial resolution of the RS data was $30 \mathrm{~m}$, and (v) the median number of REDD+ activities that RS data was used for operational monitoring of was 1 (typically deforestation). Many new sources of RS data have become available in recent years, so complementary or alternative RS data sets for generating future FRELs can potentially be identified based on our findings; e.g. alternative RS data sets could be considered if they have similar or higher quality/quantity than the currently-used data sets.
\end{abstract}

\section{INTRODUCTION}

\subsection{REDD+ Forest Reference Emission Levels (FRELs)}

In 2010, developing countries were encouraged by the United Nations Framework Council on Climate Change (UNFCCC) to reduce greenhouse gas emissions from five activities associated with forest land: (1) deforestation, (2) forest degradation, (3) sustainable management of forests, (4) forest carbon stock conservation, and (5) forest carbon stock enhancement; i.e. REDD+ (UNFCCC, 2010). In the same statement, i.e. Decision $1 / \mathrm{CP} .16$, it was stipulated that countries wishing to receive financial, technical, and technological support for these activities must develop a national or sub-national (as an interim measure) forest reference emission level (FREL). A FREL (in tons $\mathrm{CO}_{2}$ emissions per year) is given for a specific timeframe in the future and based on historical emissions from one or more REDD+ activities, with adjustments due to national circumstances allowed (UNFCCC, 2011). The FREL serves as a baseline for measuring the country's performance in mitigating climate change through activities on forested land.

\subsection{FREL Generation Using Remote Sensing Data}

Methods which can be used to estimate historical emissions and generate FRELs based on these historical estimates are quite flexible to allow for differences in national circumstances/capacities and to permit FRELs to be improved over time as national capacities and data quality/quantity improve (UNFCCC, 2011). However, UNFCCC Decision 4/CP.15 states that the historical emissions must be calculated based on a combination of remote sensing (RS) and ground-based forest carbon inventory (GBFCI) approaches (UNFCCC, 2009). Thus the quality and quantity of the RS and GBFCI data will have an impact on the accuracy of the historical emissions estimates. New sources of high quality (and in many cases free) RS data are becoming available almost every year, so it is reasonable to expect that the quality (e.g. spatial resolution) and quantity (e.g. spatial coverage and temporal resolution) of the RS data used for FREL generation should increase over time.

In this study, we calculated five metrics to assess the quality and quantity of RS data used in the current FRELs (i.e. those already submitted to the UNFCCC as of Dec. 2015). The metrics were calculated for each country, and median values were considered to represent the typical RS data being used for the current FRELs. If we assume that the quality and quantity of RS data used for FREL generation should increase over time (due to the increasing number of RS data sources), the median values calculated in this study can potentially be used to help identify new complementary or alternative RS data sources for future FRELs.

\section{METHODS}

\subsection{Data}

By the end of 2015, six countries had submitted reports for technical review to the UNFCCC secretariat containing the details of their proposed FRELs, in line with Decision 12/CP.17: Brazil (Ministry of the Environment and Ministry of Science,

Corresponding author 
Technology, 2014), Colombia (Ministry of Environment and Sustainable Development and Institute of Hydrology, 2014), Ecuador (Ministry of Environment, 2014), Guyana (Government of Guyana, 2014), Malaysia (Ministry of Natural Resources and Environment, 2014), and Mexico (Secretary of Environment and Natural Resources and National Foresty Commission, 2014). These reports contain information on the type(s) of RS data the countries used for estimating historical emissions, as well as how these historical emissions estimates were used to generate their FRELs. As recommended in the Intergovernmental Panel on Climate Change's Good Practice Guidance for LULUCF (2003), all six countries used the RS data to produce maps of forest extent and forest change over time (i.e. using image classification algorithms) and the GBFCI to calculate the resultant $\mathrm{CO}_{2}$ emissions from these changes. As shown in Figure 1, the countries that have already submitted their proposed FREL are all located in the Americas and Southeast Asia.

\subsection{RS Data Quality/Quantity Metrics}

Based on the information provided in the country reports, five metrics were calculated to assess the quality and quantity of the RS data being used to generate FRELs:

(i) Percentage of country mapped using RS data;

(ii) Historical timeframe (in years) over which RS data was used to monitor forest changes;

(iii) Average interval of forest map updates in years, i.e. $\frac{\text { historical time frame in years }}{\text { \# of maps produced }-1}$

(iv) Spatial resolution of the RS data;

(v) Number of REDD+ activities the RS data was used to monitor for generating the FREL.

Of these metrics, (i)-(iii) are indicators of the RS data quantity (area extent and temporal resolution), (iv) is an indicator of the data quality because it determines the minimum changes in forest extent that can be detected, and (v) is another indicator of the data quality because the types/number of REDD+ activities that RS data can be used to monitor is limited by the quality of the data. For countries that generated multiple FRELs for different time periods, the value reported in (ii) is the historical timeframe used for the most recent FREL. Additionally, some countries used forest maps from outside the designated historical timeframe to help with FREL generation (i.e. they interpolated the forest extent at the starting/ending period of the timeframe using maps before/after the end of the timeframe), so in these cases, for both (ii) and (iii) we modified the historical timeframe to match the first and last image dates (to reflect the actual RS data used). For countries that used multiple RS data sources (e.g. because finer spatial resolution data became available in more recent years), the value reported for (iv) was that of the coarsest resolution data set because this data set limits the finest-scale forest changes that can be detected over the historical timeframe. Finally, for (v), some countries monitored historical emissions for multiple REDD+ activities using RS data, but did not consider all of them for generating their FREL (e.g. due to an unacceptable level of estimation uncertainty), so the value reported in (v) is limited to the number of REDD+ activities actually considered for generating the FREL. After calculating all of these metrics at the country level, median values were computed.

\section{RESULTS AND DISCUSSION}

The values calculated for metrics (i)-(v) are reported in Table 1. As can be seen in the table: (i) the percentage of each country mapped using RS data ranged from $40 \%$ to $100 \%$ with a median value of $100 \%$; (ii) the historical timeframe RS data was used for ranged from 8 to 20 years with a median value of 11.5 years; (iii) the interval of forest map updates ranged from 1 to 8 years with a median value of 4.5 years; (iv) the spatial resolution of the RS data for all countries was $30 \mathrm{~m}$ (although some countries also used finer-resolution data in more recent years); and (v) all countries used RS data to estimate emissions for one REDD+ activity, deforestation, with the exception of Malaysia, which monitored sustainable management of forests. Another important observation is that all countries used only optical RS data.

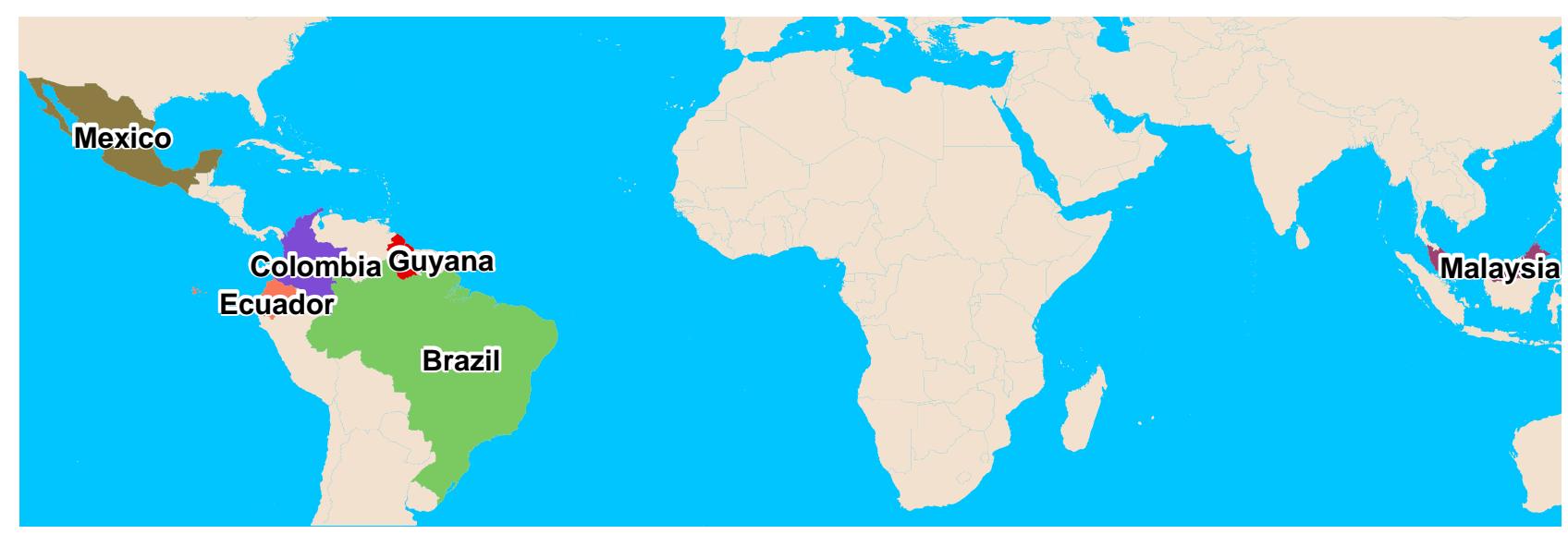

Figure 1. Countries that have submitted proposed FRELs to the UNFCCC, as of Dec. 2015. 


\begin{tabular}{|c|c|c|c|c|c|}
\hline Country & $\begin{array}{c}\text { (i) \% of country } \\
\text { mapped using RS data }\end{array}$ & $\begin{array}{c}\text { (ii) Historical } \\
\text { timeframe (in years) }\end{array}$ & $\begin{array}{c}\text { (iii) Average interval } \\
\text { of forest map } \\
\text { updates (in years) }\end{array}$ & $\begin{array}{c}\text { (iv) Spatial } \\
\text { resolution of RS } \\
\text { data }\end{array}$ & $\begin{array}{c}\text { (v) \# REDD+ activities monitored by RS } \\
\text { for FREL generation }\end{array}$ \\
\hline Brazil & $49 \%$ & 14 & 1 & $30 \mathrm{~m}$ & 1 (deforestation) \\
Colombia & $40 \%$ & 12 & 2 & $30 \mathrm{~m}$ & 1 (deforestation) \\
Ecuador & $100 \%$ & 8 & 8 & $30 \mathrm{~m}$ & 1 (deforestation) \\
Guyana & $100 \%$ & 11 & 2 & $30 \mathrm{~m}$ & 1 (deforestation) \\
Malaysia & $100 \%$ & 20 & 7 & $30 \mathrm{~m}$ & 1 (sustainable management of forests) \\
Mexico & $100 \%$ & 8 & 8 & $30 \mathrm{~m}$ & 1 (deforestation) \\
Median & $\mathbf{1 0 0 \%}$ & $\mathbf{1 1 . 5}$ & $\mathbf{4 . 5}$ & $\mathbf{3 0 ~ m}$ & $\mathbf{1}$ \\
\hline
\end{tabular}

Table 1. Values for metrics (i)-(v) by country. Median value of each metric shown in bold text.

As one example of how our findings could be helpful for the preparation of future FRELs, countries that have already submitted their FRELs could use the information given in Table 1 to identify some aspects of RS data quality/quantity to improve in their subsequent FREL submissions. Our results may also provide some useful search criteria to help countries identify complementary or alternative RS data sources to use for their future FREL submissions. For example, if we use the median values of each metric as minimum requirements for this search, a new RS data source could be considered if it has: (i) data coverage for $100 \%$ of the country, (ii) a historical timeframe of 11.5 years or greater, (iii) the potential to acquire cloud-free (or near cloud-free) imagery every 4 years or less, (iv) a spatial resolution of $30 \mathrm{~m}$ or finer, and (v) the potential to be used for monitoring and estimating emissions for 1 or more REDD+ activity. Synthetic Aperture Radar (SAR) EO data has frequently been suggested as a potential complementary data source for REDD+ (Reiche et al., 2016), and many free high resolution SAR data sets have become available in recent years (e.g. $25 \mathrm{~m}$ resolution ALOS PALSAR-1/PALSAR-2 mosaic data starting from 2007, 5-20 m resolution Sentinel-1 data from 2014), so if the median values we calculated are considered as minimum requirements then PALSAR-1/PALSAR-2 mosaic data could be used in combination with optical data starting from 2020 and/or Sentinel-1 data could be used from 2026. The Committee on Earth Observation Satellites (CEOS) provides a searchable online database with the details of many current and future satellite missions, which could provide further aid in this type of searching (Committee on Earth Observation Satellites, 2016).

There are some limitations to this study which we would like to point out. One is that we calculated the RS data quality/quantity metrics using only the information provided by the countries that already submitted their proposed FRELs to the UNFCCC (as of Dec. 2015), while many other developing countries will submit their reports in 2016 or later. Thus our results are based on just a sample of all the proposed FRELs that can be expected. Another limitation is related to the metrics, as such a small number of metrics cannot fully capture the quality and quantity of the RS data used for generating the FRELs. Although additional metrics could surely be computed to provide additional information on the data quality/quantity, we focused on just a few which could be helpful for identifying new potential RS data sources. As one example, spectral resolution is often considered as another indicator of RS data quality, but a spectral resolution metric may not be useful for identifying new complementary data sources which have a low spectral resolution but provide other advantages (e.g. ability to penetrate cloud cover or sensitivity to vegetation biomass, as with SAR data (De Sy et al., 2012; Hoan et al., 2013; Reiche et al., 2015)).

\section{CONCLUSIONS}

In this study, we assessed the quality and quantity of the remote sensing (RS) data used to generate national/sub-national forest reference emission levels (FRELs) related to REDD+ activities. We found that for some RS data quality/quantity metrics including (i) percentage of country mapped using RS data, (ii) historical timeframe over which RS data was used to monitor forest change, and (iii) average interval of forest map updates, there was significant variation between countries. For other metrics including (iv) spatial resolution of the RS data and (v) Number of REDD+ activities the RS data was used to monitor, there was no variation between countries. We hope our results can be used to identify potential areas for improvement of RS data quality/quantity in subsequent FREL submissions, and/or to identify new complementary/alternative RS data sources for generating FRELs in the future.

\section{ACKNOWLEDGEMENTS}

This project was supported by the Research Institute of Science and Technology for Society (RISTEX), the Japan Science and Technology Agency (JST). We would also like to thank Matthew Steventon and Stephen Ward of Symbios Communications for their helpful comments and suggestions.

\section{REFERENCES}

Committee on Earth Observation Satellites, 2016. The CEOS Database [WWW Document]. URL http://database.eohandbook.com/index.aspx (accessed 3.30.15).

De Sy, V., Herold, M., Achard, F., Asner, G.P., Held, A., Kellndorfer, J., Verbesselt, J., 2012. Synergies of multiple remote sensing data sources for REDD+ monitoring. Curr. Opin. Environ. Sustain. 4, 696-706.

Government of Guyana, 2014. The Reference Level for Guyana's REDD+ Program.

Hoan, N.T., Tateishi, R., Alsaaideh, B., Ngigi, T., Alimuddin, I., Johnson, B., 2013. Tropical forest mapping using a combination of optical and microwave data of ALOS. Int. J. Remote Sens. 34, 139-153.

Intergovernmental Panel on Climate Change, 2003. Good Practice Guidance for Land Use, Land-Use Change and Forestry. Institute for Global Environmental Strategies, Hayama, Japan.

Ministry of Environment, 2014. Ecuador's Forest Reference Emission Level for Deforestation.

Ministry of Environment and Sustainable Development, Institute 
of Hydrology, M. and E.S., 2014. Proposed Forest Reference Emission Level for deforestation in the Colombian Amazon Biome for results-based payments for REDD+ under the UNFCCC.

Ministry of Natural Resources and Environment, M., 2014. Malaysia's Submission on Reference Levels for REDD+ Results Based Payments under UNFCCC.

Ministry of the Environment, Ministry of Science, Technology, and I., 2014. Brazil's submission of a forest reference emission level for deforestation in the Amazonia biome for results-based payments for REDD+ under the UNFCCC.

Reiche, J., Lucas, R., Mitchell, A.L., Verbesselt, J., Hoekman, D.H., Haarpaintner, J., Kellndorfer, J.M., Rosenqvist, A., Lehmann, E.A., Woodcock, C.E., Seifert, F.M., Herold, M., 2016. Combining satellite data for better tropical forest monitoring. Nat. Clim. Chang. 6, 120-122. doi:10.1038/nclimate2919

Reiche, J., Verbesselt, J., Hoekman, D., Herold, M., 2015. Fusing Landsat and SAR time series to detect deforestation in the tropics. Remote Sens. Environ. 156, 276-293.

Secretary of Environment and Natural Resources, National Foresty Commission, 2014. National forest reference emission level proposal México.

UNFCCC, 2011. Decision 12/CP.17.

UNFCCC, 2010. Decision 1/CP.16.

UNFCCC, 2009. Decision 4/CP.15. 